\title{
An investigation on using measurement uncertainty as decision rule for statement of conformity
}

\author{
Gouda M. Mahmoud*1, Riham S. Hegazy ${ }^{1}$
}

\section{Edited by}

Juan Carlos Salcedo-Reyes

salcedo.juan@javeriana.edu.co

1. National Institute of Standards, Tersa St, El-Haram, Box 136 Code 12211,

Giza, Egypt

*Goudamohamed15@yahoo.com

Received: $24-03-2020$

Accepted: 26-05-2021

Published online: 12-07-2021

Citation: Mahmoud G, Hegazy RS. An investigation on using measurement uncertainty as decision rule for statement of conformity, Universitas Scientiarum, 26(2): 179-191, 2021.

doi: 10.11144/Javeriana.SC26-2.aiou

Funding: N.A.

Electronic supplementary material: N.A.

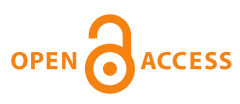

\begin{abstract}
This research article refers to the application of the evaluated measurement uncertainty for deciding the statement of conformity. It is a proposal to rethink about the classification of measuring devices, taking into account the calculations of uncertainty as a decision rule. It is also a base for complete compatibility and harmonization between ISO 17025:2017 and the other standards. To verify this proposal a case study on compression testing machine classification is used. This proposal aims to review classification criteria for these machines. Since the uncertainty value is equivalent to all parameters that may affect the performance of these machines, it is logical and accurate to use it as the basis for the classification. This approach may be employed for the upcoming version of ISO 7500 standard to use the uncertainty value as a base for machine classification.
\end{abstract}

Keywords: Conformity statement; confidence level; decision rule; uncertainty estimation.

\section{Introduction}

Better measurements mean to provide credible and delicate decision for calibration and testing in industrial processes and quality assurance output. Measurement is specified as the practice by which operative evaluation is ensured [1]. Statistically estimated errors are not adequate to identify the results of the measurements. It is clearly recognized that, when all the doubtful or specified error components have been estimated, and the proper rectification has been exercised, there is still a remnant of uncertainty about the rectifications of the resultant value, that is, a doubt about how far the results of the measurement clarify the values acquired from the measurand under "calibration" as described by the guideline to the expressions of the measurements uncertainty (GUM) [2]. Based on metrological background the uncertainty related to the measurement activity is an important part for assessing the acquired values. Due to measurement uncertainty, usually there is risk of incorrect decisions. Incorrect decisions can be of two types: the first is false acceptance or customer's risk for items accepted as conforming that may actually be non-conforming. The second is false rejection or producer's risk for items rejected as non-conforming that may actually be conforming, see Figure 1. Decision rules for conformity are required at the present time in different critical application areas, like monitoring and controlling of environmental conditions, and testing for products, but without a predefined basis for assessing the risks that may arise from the measurement uncertainties between the consumers and the suppliers [6]. In order to make a decision to provide a conformity statement for a specific instrument, the results of calibrating this instrument should be accompanied by its measurement uncertainty, 'expanded' uncertainty $U$. The interval of measurement uncertainty is often $y \pm U$ [3]. 


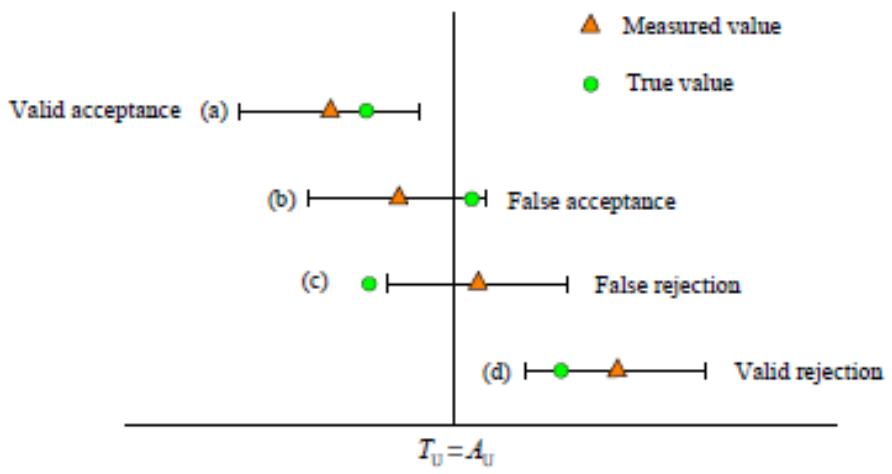

Figure 1. Acceptance introduction and rejection.

The two main stages in uncertainty utilization in decision-making are:

1. Setting a limit on a maximum permissible measurement uncertainty (MPU);

2. Allowing for risks due to uncertainty by sharing risk.

Shared risk, on the other hand, is an agreement between the interested parties concerned with the outcome of the testing results that neither will be given an advantage or disadvantage with the consideration of measurement uncertainty. Implicit in such an agreement is that the expanded measurement uncertainty $U_{\text {exp }}$ is 'small' with respect to the MPE (Maximum permissible error) (i.e. the ratio ( $\left.U_{\exp } / \mathrm{MPE}\right)$ is 'small') so that significant risk of an erroneous decision exists for values of $\bar{E}_{\mathrm{I}}$ that are only very close to the MPE boundaries. This is illustrated in Figure 2 for two possible different PDFs for a given measurement. The uncertainty $U_{\text {exp }}$ associated with the leftmost (red) Gaussian curve is probably too large for a shared risk arrangement, whereas the uncertainty $U_{\text {exp }}$ associated with the rightmost (green) Gaussian curve would probably be acceptable for most applications, refer to Figure 2 [4].

Probability Density Function (PDF)

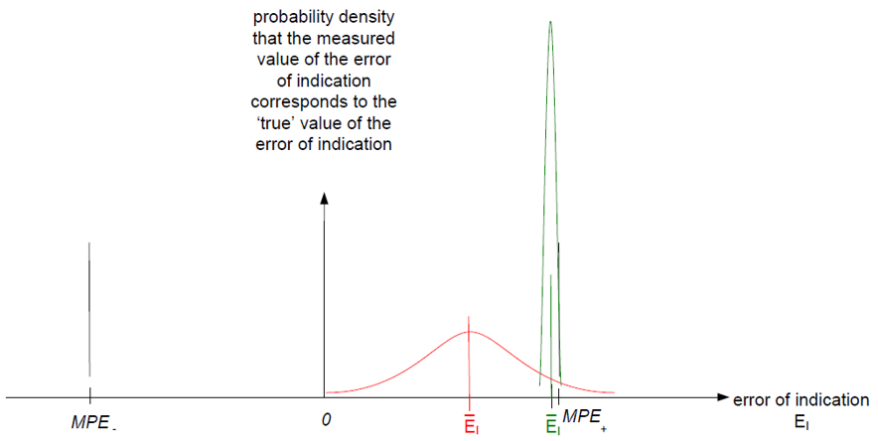

Figure 2. The agreement between MPE and expanded uncertainty at different PDF. 
Note that with the shared risk approach it is still necessary to calculate the measurement uncertainty $U_{\text {exp }}$ so that the ratio $\left(U_{\exp } / \mathrm{MPE}\right)$ can be examined to see if it is 'small enough'. Also note that if the maximum permissible errors are to be adjusted for some reason (for example, allowance for in-service conditions) using the guard band method, the shared risk approach can still be used with the new or guard banded MPEs [5].

\section{Experimental work}

The different components participating in the measurement uncertainty of budget evaluation are identified by fishbone diagrams simulated by the statistician of quality control. The fishbone diagram is an effective tool for analysis. The fishbone diagram stipulates methodical means for investigating the contributions of all components and their occasions that participate in the final evaluation [6]. The fishbone diagrams for estimating the uncertainty and its related components are shown in Figure 3. The testing machine used in this investigation is calibrated and the associated uncertainty of the measurand is estimated. The calibration process is conducted in accordance with ISO 7500-1-2018" Metallic materials, verification, calibration and static testing machines, uniaxial compression/tension testing machine [7]. The reference value and calibration equation at various calibration points is obtained using a reference load cell $5 \mathrm{kN}$. This force transducer is classified as class 0.0 , based on the calibration which was conducted on the primary standard dead weight machine [8]. This standard machine employs SI units and achieves the traceability chain for force measurements. The measurement traceability is maintained where it is traceable by National Institute of Standards (NIS) of Egypt which is seeking international recognition and has maintained Calibration and Measurement Capabilities (CMCs) recorded at International Bureau of Weights and Measures (BIPM). This force transducer was used to calibrate the machine under investigation, refer to Figure 4.

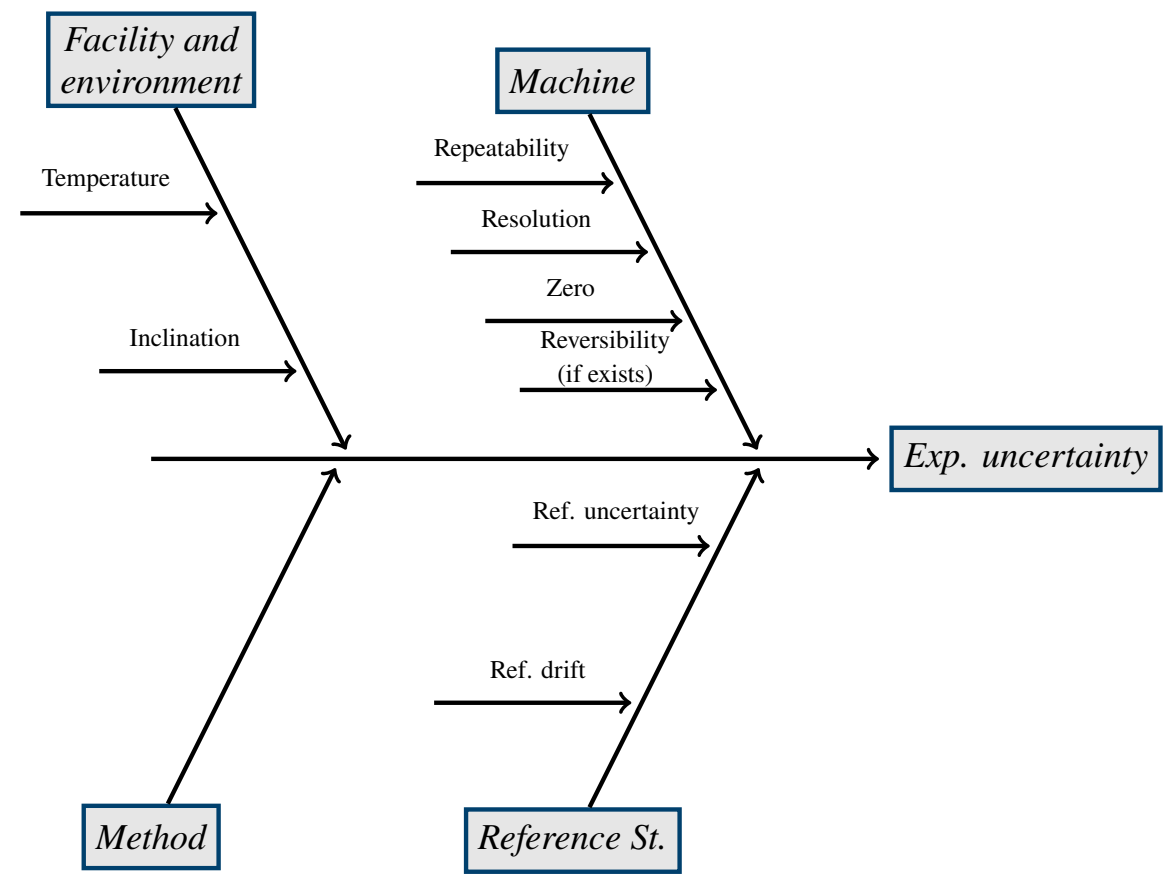

Figure 3. Fishbone diagram for uncertainty parameter in calibration of compression testing machine. 


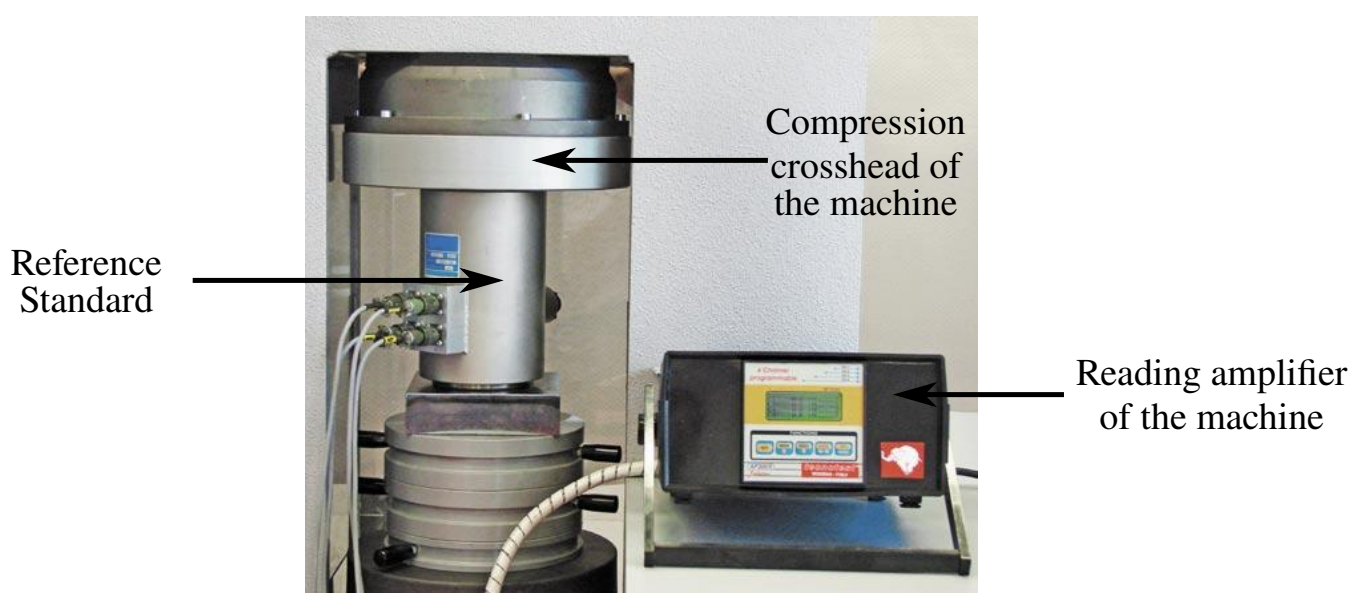

Figure 4. The experimental work setup.

As the calibrations processes are automated, the impressing components are reduced. The way used for identifying and estimating the components of uncertainty was according to the GUM for evaluating uncertainty, which is in line with the uncertainty procedure mentioned in ISO 7500;2018, see Table 1.

\subsection{The relative errors of the calibration}

From ISO 7500:2018 the following equations can be used to calculate the relative errors [9];

Table 1. The calibration results of the machine under investigation.

\begin{tabular}{ccccc}
\hline \multicolumn{5}{c}{ Calibration results } \\
\hline \multirow{2}{*}{ Nominal load } & \multirow{2}{*}{ Actual load } & \multicolumn{4}{c}{ Relative error of } \\
\cline { 3 - 5 } & & $q_{1}$ & $b$ & $a$ \\
\hline $\mathrm{N}$ & $\mathrm{N}$ & $\%$ & $\%$ & $\%$ \\
\hline 250 & 250.31 & -0.123 & 0.399 & 0.004 \\
500 & 501.79 & -0.357 & 0.299 & 0.00199 \\
750 & 751.29 & -0.171 & 0.266 & 0.00133 \\
1000 & 1002.13 & -0.212 & 0.299 & 0.001 \\
1250 & 1252.81 & -0.224 & 0.199 & 0.0008 \\
1500 & 1501.85 & -0.123 & 0.2 & 0.00067 \\
1750 & 1752.23 & -0.127 & 0.114 & 0.00057 \\
2000 & 2003.63 & -0.181 & 0.025 & 0.0005 \\
2250 & 2251.71 & -0.076 & 0.2 & 0.00044 \\
2500 & 2504.98 & -0.199 & 0.12 & 0.0004 \\
\hline Machine is classified as Class 0.5 as per ISO 7500-1-2018 \\
\hline
\end{tabular}




\subsubsection{Relative indication error (accuracy)}

For each calibrated force, the accuracy can be calculated from the following formula;

$$
q_{1}=\frac{F_{i 1}-F_{1}}{F_{1}} \times 100
$$

$F_{i}$ : Force displayed by the force readout of the testing machine.

$F_{i 1}$ : The subscripts 1,2 , and 3 represent the readings and calculated values from the three series of runs at each force level.

\subsubsection{The relative repeatability error $(b)$}

The relative repeatability error can be calculated from the following equation;

$$
b=q_{\max }-q_{\min }
$$

$q_{\max }$ : The maximum value of the measured values at each calibrated point of the measuring system of the testing machine.

$q_{\min }$ : The minimum value of the measured values at each calibrated point of the measuring system of the testing machine.

\subsubsection{The relative resolution (a)}

The relative resolution $a$ of the force readout is defined by the following formula;

$$
a=\frac{r}{F_{i}} \times 100,
$$

where $r$ is the resolution of the testing machine readout.

The calibration results of the machine under investigation were recorded and the relative errors were calculated based on the previous equations. This calibration was conducted in accordance with ISO 7500-1:2018. Three trails were conducted and the average response of the reference force transducer was recorded to represent the actual load Table 1.

\section{Problem analysis}

In accordance with the following Table 2, the classification decision does not take in to account the budget uncertainty which is considered as conformity statement in accordance with ISO 17025:2017. ISO 17025:2017 stated that decision rules should be taken into consideration when providing the conformity statement [10]. This decision rule should take into consideration the uncertainty budget. Based on Guidelines on Decision Rules and Statements of Conformity. It is necessary to take into account the uncertainty budget of the measured quantity when it is required to determine the conformity statement such as pass/fail, tolerance, classifications, etc. [11].

The aim of this proposal is to consider the requirement of ISO 17025:2017 and ISO 7500:2018 regarding the classification criterion. 
Table 2. The classification criteria for the force-measuring system.

\begin{tabular}{|c|c|c|c|c|c|}
\hline \multirow{3}{*}{ Class of machine } & \multicolumn{5}{|c|}{$\begin{array}{c}\text { Maximum permissible value } \\
\%\end{array}$} \\
\hline & \multicolumn{4}{|c|}{ Relative error of } & \multirow{2}{*}{$\begin{array}{c}\text { Relative } \\
\text { resolution } \\
(a)\end{array}$} \\
\hline & Indication error $(q)$ & $\begin{array}{c}\text { Repeatability } \\
(\text { b })\end{array}$ & $\begin{array}{c}\text { Reversibility* } \\
(v)\end{array}$ & $\begin{array}{l}\text { Zero } \\
\left(f_{0}\right)\end{array}$ & \\
\hline 0.5 & \pm 0.50 & 0.50 & \pm 0.750 & \pm 0.050 & 250 \\
\hline 1 & \pm 1.00 & 1.00 & \pm 1.500 & \pm 0.10 & 0.5 \\
\hline 2 & \pm 2.00 & 2.00 & \pm 3.00 & \pm 0.20 & 1.00 \\
\hline 3 & \pm 3.00 & 3.00 & \pm 4.50 & \pm 0.30 & 1.50 \\
\hline
\end{tabular}

* The relative reversibility error is only determined when required.

\section{Results and discussion}

During this investigation the contribution of each parameter has been identified and the expanded uncertainty has been estimated. To evaluate the contribution of each uncertainty component the following formulas were used [12].

\subsection{The uncertainty due to repeatability}

The repeatability can be calculated from the following formula;

$$
u_{\text {rep }}=\sqrt{\frac{1}{n(n-1)} \sum_{i=1}^{n}\left(q_{i}-q\right)^{2}}
$$

where:

$n$ is the number of readings at each nominal force level;

$q_{i}$ is the measured error at the nominal force level (\%);

$q$ is the mean measured error at the nominal force level (\%).

\subsection{The uncertainty due to drift}

The drift for the calibrated machine between two external calibrations is estimated from the two last calibration certificates. For a given point, the maximum difference (absolute value) is calculated from the corrections of each certificate $\Delta c$. The uncertainty component is estimated by the following formula;

$$
\text { drift }=\frac{\max (\Delta c)}{\sqrt{3}}
$$

where $\max (\Delta c)$ is the maximum difference between the calculated errors from the last two calibration certificates for this machine. 


\subsection{The uncertainty due to zero error}

The relative zero error of each series calculated shall be noted using formula (3):

$$
f_{0}=\frac{F_{i 0}}{F_{N}} \times 100
$$

where $F_{i 0}$ is the residual indication of the force indicator of the testing machine to be verified after removal of force (in Newtons), and $F_{N}$ is the maximum value of the calibrated range of the force indicator of the testing machine (in Newtons).

$$
U_{\text {zero }}=\frac{f_{0}}{\sqrt{3}}
$$

\subsection{The uncertainty due to inclination}

$$
u_{\text {inc }}=\frac{F-F \cos \theta}{F} \times 100
$$

Here $\theta$ is given in degrees and equal to 1 degree as specified by ISO 7500-1:2018, and $F$ is the reference force indicated by the force-proving instrument with increasing test force.

\subsection{The uncertainty contribution due to force measurement by reference force transducer}

$U_{\text {stnd }}$ can be calculated as the expanded uncertainty value mentioned in the reference force transducer calibration certificate used in calibration divided by $k$ as coverage factor (in most cases $k=2$ )

$$
U_{\text {stnd }}=\frac{U_{\text {ref }}}{2}
$$

where $U_{\text {ref }}$ is the expanded uncertainty value mentioned in the reference force transducer calibration certificate.

\subsection{The uncertainty contribution due to temperature measurements by a calibrated hy-} grometer

$U_{\text {temp }}$ the uncertainty budget calculated from the calibration certificate of the hygrometer at a given temperature. During the calibration process it is not fully guaranteed that the temperature is exactly the same, but it remains in a given range. It can be calculated from the following formula

$$
U_{\text {temp }}=\frac{U_{\text {cal cer Hyg }}}{2 \sqrt{3}}
$$

Table 3. The uncertainty component for point $250 \mathrm{~N}$

\begin{tabular}{cccccccc}
\hline $\begin{array}{c}U_{\text {std }} \\
\mathbf{\%}\end{array}$ & $\begin{array}{c}U_{\text {drift }} \\
\mathbf{\%}\end{array}$ & $\begin{array}{c}U_{\text {temp }} \\
\mathbf{\%}\end{array}$ & $\begin{array}{c}U_{\text {rep }} \\
\mathbf{\%}\end{array}$ & $\begin{array}{c}U_{\text {zero }} \\
\mathbf{\%}\end{array}$ & $\begin{array}{c}U_{\text {res }} \\
\mathbf{\%}\end{array}$ & $\begin{array}{c}U_{\text {Inc }} \\
\mathbf{\%}\end{array}$ & $\begin{array}{c}* U_{\text {exp }} \\
\mathbf{\%}\end{array}$ \\
\hline 0.002 & 0.011547 & 0.0144338 & 0.1443376 & 0.0144338 & 0.1443376 & 0.0011547 & 0.41 \\
0.002 & 0.011547 & 0.0144338 & 0.2886751 & 0.0288675 & 0.2886751 & 0.0017321 & 0.82 \\
0.01 & 0.011547 & 0.0144338 & 0.5773503 & 0.057735 & 0.5773503 & 0.0028868 & 1.64 \\
0.025 & 0.011547 & 0.0144338 & 0.8660254 & 0.0866025 & 0.8660254 & 0.0028868 & 2.46 \\
\hline
\end{tabular}

*Uexp calculated from equation 2 with a coverage factor of 2 at confedence level of $95 \%$. 
where $U_{\text {cal cer Hyg }}$ is the expanded uncertainty value mentioned in the hygrometer calibration certificate divided by $k$, as coverage factor (in most cases $k=2$ ) and it also divided by $\sqrt{3}$ where it is a rectangular distribution.

\subsection{The uncertainty due to resolution}

$$
U_{\text {res }}=\sqrt{\left(\frac{a_{F}}{2 \sqrt{3}}\right)^{2}+\left(\frac{a_{z}}{2 \sqrt{3}}\right)^{2}}
$$

where $a_{F}$ is the relative resolution of the force indicator of the testing machine at the applied force and $a_{z}$ is the relative resolution of the force indicator of the testing machine at zero force.

\subsection{The combined uncertainty and expanded uncertainty}

The combined uncertainty can be calculated from the following formula

$$
u_{c}\left(y \times\left(x_{1}, \ldots, x_{n}\right)\right)=\sqrt{\sum_{n=1}^{n} c_{i}^{2} u\left(x_{i}\right)^{2}}=\sqrt{\sum_{n=1}^{n} u\left(y, x_{i}\right)^{2}}
$$

where $y\left(x_{1}, x_{2}\right)$ is a function of several components $x_{1}, \ldots, x_{n} ; c_{i}$ is the sensitivity coefficient estimated as the partial differential of $y$ with respect to $x_{i}$ and $u\left(y, x_{i}\right)$.

\subsection{The expanded standard uncertainty}

The expanded uncertainty of the calibration results can be calculated from the following formula

$$
U_{\exp }=k \times u_{c}=k \times \sqrt{\sum_{i=1}^{n} u_{i}^{2}}
$$

where: $k$ is defined as the coverage factor ( 2 at $95 \%$ confidence level).

$u_{c}$ is defined as the combined uncertainty.

$u_{1}$ to $u_{n}$ are the related standard uncertainties.

In the previous table and figures the conformity assessment was conducted based on the expanded uncertainty value (proposed classification criteria). Shared risk (the shared risk can reach up to $50 \%$ of a false acceptance or a false rejection of the analyzed item) was taken into account.

Table 4. The uncertainty budget for point $250 \mathrm{~N}$

\begin{tabular}{ccccc}
\hline $\begin{array}{c}\text { Nominal load } \\
\text { Newton }\end{array}$ & $\begin{array}{c}\text { Actual load } \\
\text { Newton }\end{array}$ & $\begin{array}{c}\text { Accuracy } \\
\text { value (proposed classification criteria)* } \\
(\%) \pm\end{array}$ & $\begin{array}{c}\text { Proposed } \\
\text { class* }\end{array}$ \\
\hline 250 & 251.25 & -0.5 & 0.5 & 0.5 \\
250 & 252.53 & -1 & 1 & 1 \\
250 & 255.1 & -2 & 2 & 2 \\
250 & 257.73 & -3 & 3 & 3 \\
\hline
\end{tabular}

* The uncertainty Uexp values were approximated to two significant figures. 
(a)

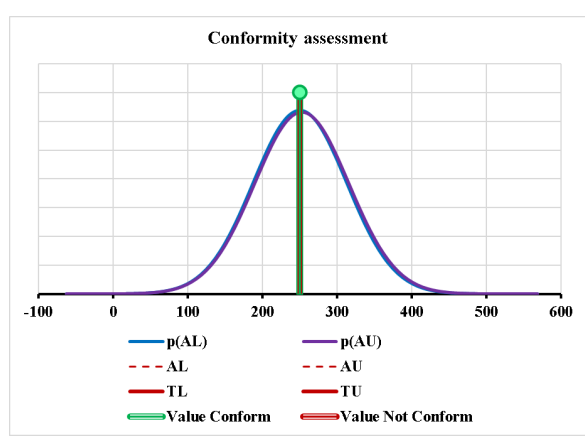

(c)

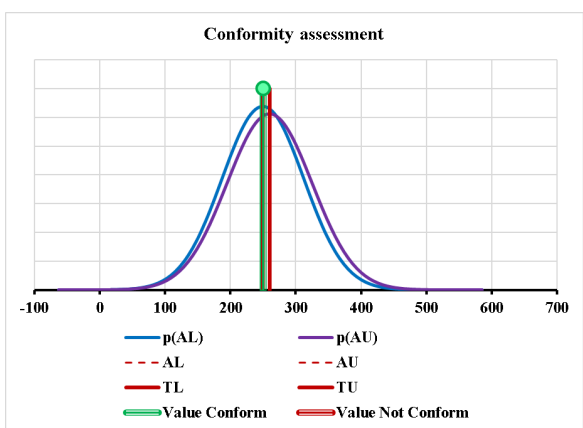

(b)

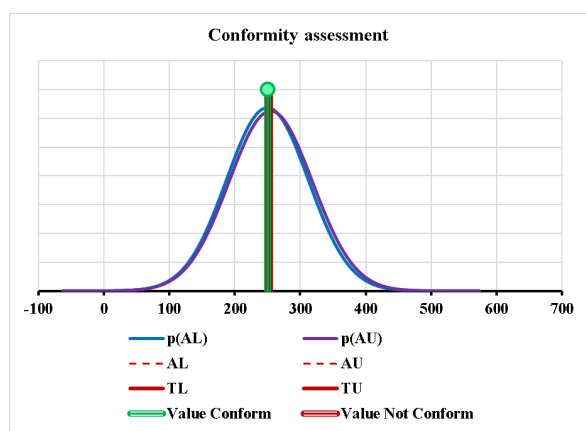

(d)

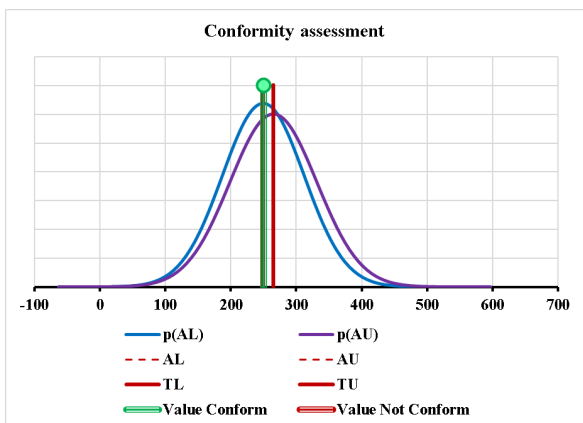

Figure 5. Conformity assesment for point $250 \mathrm{~N}$ at uncertainties (a) $\pm 0.5 \%$, (b) $\pm 1 \%$, (c) $\pm 2 \%$, and (d) $\pm 3 \%$.

The measured value is conforming if equal or between the lower acceptance limit and the upper acceptance limit, taking into account the relative expanded uncertainty. Guard band is considered to be equal to 0.0 . The probability density at the lower acceptance limit $p(\mathrm{AL})$, the probability density at the upper acceptance limit $p(\mathrm{AU})$, as well as AL - Lower acceptance limit; AU - Upper acceptance limit; TL - Lower tolerance limit; and TU - Upper tolerance limit were represented. Through the previous figures (Figure 5) and Table 5 it became clear to what extent the proposed classification criteria conform to the calculations that were made. Hence, it was concluded that it is more realistic and accurate to take into account the value of uncertainty as a prerequisite for the classification. Shared risk has to be considered to avoid false positive or false negative.

Table 5. Modified classification criterion based on the newly developed proposal.

\section{Class of machine}

Exp. uncertainty value (proposed classification criteria)*

$(\%) \pm$

\begin{tabular}{cc}
\hline 0.5 & 0.5 \\
1 & 1 \\
2 & 2 \\
3 & 3 \\
\hline * The uncertainty Uexp values were approximated to two significant figures. \\
\hline
\end{tabular}




\section{Conclusion}

In this article a proposed classification approach was developed. This proposal mainly deals with the idea of using the uncertainty value as the basis for the classification decision. Risk has to be taken into account when using uncertainty to prevent false positives or false negatives. In this article shared risk was used where the shared risk can reach up to $50 \%$ of a false acceptance, or a false rejection of the analyzed item. To confirm the results of this proposal, the results of calibration of a compression machine were used. It is mentioned that this machine has been calibrated according to the ISO 7500 standard. From the previous results it was concluded that it is recommended to rethink about the classification of measuring devices, taking into account the calculations of uncertainty. It is also rooted in the harmonization between ISO 17025:2017 and the other standards such as ISO 7500:2018 classification criterion. Since the expanded uncertainty is equivalent to the other components mentioned in the calibration standard methods, but it is more realistic and more accurate, it is more accurate and more realistic to be included as a decision rule when classifying the calibrated equipment. It is possible to suggest more research on this topic in the future, taking into account the different risk situations such as customer risks and producer risks separately.

\section{References}

[1] JCGM. 100 Guide to the Expression of Uncertainty in Measurement (GUM), and its supplements, Joint Committee on Guides in Metrology, 2008.

doi: https://www.bipm.org/documents/20126/2071204/JCGM_100_2008_E.pdf/cb0ef43fbaa5-11cf-3f85-4dcd86f77bd6.

[2] JCGM. 102 Evaluation of measurement data - Supplement 2 to the Guide to the expression of uncertainty in measuremen - Extension to any number of output quantities Joint Committee on Guides in Metrology, 2011.

doi: https://www.oiml.org/en/files/pdf_g/g001-102-e11.pdf

[3] Sniazhana S. Uncertainty in decision-making: A review of the international business literature, Cogent Business \& Management, 6: 1-32,2019.

doi: $10.1080 / 23311975.2019 .1650692$

[4] Pendrill LR. Using measurement uncertainty in decision-making and conformity assessment, Metrologia, 51(4): 1-14, 2014.

doi: $10.1088 / 0026-1394 / 51 / 4 / \mathrm{S} 206$

[5] Carlo C, Francesca P. Bayesian conformity assessment in presence of systematic measurement errors, Metrologia, 53(2): 9, 2016.

doi: $10.1088 / 0026-1394 / 53 / 2 / \mathrm{S} 74$

[6] Pravakar MA. Case Study on Decision Making with Expression of Uncertainty in Measurement, IEEE Region 10 Colloquium and the third ICIIS, Kharagpur, INDIA December 8-10, 2008.

doi: 10.1109/ICIINFS.2008.4798364

Universitas Scientiarum Vol. 26(2):179-191 
[7] Emilia M. Towards improving decision making and estimating the value of decisions in value-based software engineering, the value framework, Software Quality Journal, 26: 607-656, 2018.

doi: 10.1007/s11219-017-9360-z

[8] Ahmed A, Ebtisam H, Gouda M, Ahmadein M. The resolution uncertainty associated with digital indications revisited: the inclusion of the quantization effect and the impact of noise presence in the estimation process, Metrologia, 55:883-892, 2018.

doi: https://iopscience.iop.org/article/10.1088/1681-7575/aaebb6/meta

[9] ISO 7500-1. Fifth edition - Metallic materials - Calibration and verification of static uniaxial testing machines - Part 1: Tension/compression testing machines - Calibration and verification of the force-measuring system, 2018.

doi: https://www.iso.org/standard/72572.html.

[10] ISO/IEC 17025:2017. General requirements for the competence of testing and calibration laboratories.

doi: https://www.iso.org/standard/66912.html

[11] ILAC G8:09/2019. Guidelines on Decision Rules and Statements of Conformity.

doi: https://ilac.org/latest_ilac_news/revised-ilac-g8-published/

[12] Mahmoud G, Hegazy R. Comparison of GUM and Monte Carlo methods for the uncertainty estimation in hardness measurements, International Journal of Metrology and Quality Engineering, 8: 14-20, 2017.

doi: 10.1051/ijmqe/2017014 
Una investigación sobre el uso de la incertidumbre de la medición como regla de decisión para la declaración de conformidad

Resumen: Este artículo de investigación trata sobre la aplicación de la incertidumbre de medición evaluada para decidir la declaración de conformidad. Se trata de una propuesta para repensar la clasificación de los dispositivos de medida, teniendo en cuenta los cálculos de incertidumbre como regla de decisión. También es una base para una completa compatibilidad y armonización entre ISO 17025:2017 y las otras normas. Para verificar esta propuesta se utiliza un estudio por casos sobre clasificación de máquinas de ensayo de compresión. Esta propuesta tiene como objetivo revisar los criterios de clasificación de estas máquinas. Dado que el valor de incertidumbre es equivalente a todos los parámetros que pueden afectar el rendimiento de estas máquinas, es lógico y preciso utilizarlo como base para la clasificación. Este enfoque puede emplearse para la próxima versión de la norma ISO 7500 para utilizar el valor de incertidumbre como base para la clasificación de la máquina.

Palabras Clave: Declaración de conformidad; nivel de confianza; regla de decisión; estimación de la incertidumbre.

Uma investigação sobre o uso da incerteza de medição como regra de decisão para declaração de conformidade

Resumo: Este artigo de pesquisa trata da aplicação da incerteza de medição avaliada para decidir a declaração de conformidade. É uma proposta de repensar a classificação dos dispositivos de medição, levando em consideração os cálculos de incerteza como regra de decisão. É também uma base para compatibilidade e harmonização completa entre a ISO 17025:2017 e as outras normas. Para verificar esta proposta é utilizado um estudo de caso sobre classificação de máquinas de ensaio de compressão. Esta proposta visa revisar os critérios de classificação dessas máquinas. Como o valor da incerteza é equivalente a todos os parâmetros que podem afetar o desempenho dessas máquinas, é lógico e preciso usá-lo como base para a classificação. Esta abordagem pode ser empregada para a próxima versão da norma ISO 7500 para usar o valor da incerteza como base para a classificação da máquina.

Palavras-chave: Palavras-chave: declaração de conformidade; nível de confiança; regra de decisão; estimativa de incerteza. 


\section{Gouda M. Mahmoud}

He received the Ph.D. degree in mechanical engineering from Cairo University - Faculty of Engineering where he is currently Associated Professor with National Institute of Standards of Egypt (NIS). He is NIS quality manager and the technical manager of force and material metrology lab at NIS. He is conducting research in metrology and material science.

\section{Riham S. Hegazy}

He is associated Professor at NIS, was the head of force and material metrology lab at NIS and is conducting many researches in metrology and material science. 